\title{
Pre-hospital care among victims of road traffic accident in a rural area of Tamil Nadu: A cross-sectional descriptive study
}

\author{
Saurabh R. Shrivastava, Pradeep Pandian, Prateek S. Shrivastava \\ Department of Community Medicine, Shri Sathya Sai Medical College and Research Institute, Chennai, Tamil Nadu, India
}

\begin{abstract}
Background: The World Health Organization has estimated that globally almost 1.24 million people die annually on the world's roads. The aim of the study was to assess the attributes of pre-hospital care in road traffic accidents (RTAs) victim brought to the health care establishment and to evaluate the pre-hospital trauma care provided in the rural areas of Kancheepuram district of Tamil Nadu. Materials and Methods: A cross-sectional descriptive study of 3 months duration (June 2014 to August 2014) was conducted in the Shri Sathya Sai Medical College and Research Institute, Kancheepuram. The method of sampling was universal sampling and all RTA victims satisfying the inclusion criteria were included in the study. During the entire study duration, total 200 RTA victims were included. A pre-tested semi-structured questionnaire was used to elicit the desired information after the victims of RTAs are stabilized. Ethical clearance was obtained from the Institutional Ethics Committee prior to the start of the study. Written informed consent was obtained from the study participants (patient/guardian of children) before obtaining any information from them. Data entry and statistical analysis were done using SPSS version 18. Frequency distributions and percentages were computed for all the variables. Results: Majority of the RTA victims 158 (79\%) were from the age-group of 15-45 years. Most of the accidents were reported in night time [77 (38.5\%)], on week-ends [113 (56.5\%)], and involved two-wheelers [153 (76.5\%)]. Almost $66(33 \%)$ of the victims were not aware of the existence of emergency ambulance services. Also, only 15 (7.5\%) victims were brought to the hospital in the emergency ambulance, of which only 3 victims were accompanied by a doctor. Conclusion: To conclude, the study indicates that a significant proportion of people were unaware about the emergency trauma ambulance services and the existing pre-hospital care services lack in multiple dimensions in a rural area of South India.
\end{abstract}

Key words: Pre-hospital care, road traffic accidents, rural, South India

\section{Introduction}

The World Health Organization has estimated that globally almost 1.24 million people die annually and 20 to 50 million people are exposed to non-fatal injuries on the world's roads. ${ }^{[1]}$ In-fact, young adult (15-44 years) contributes almost $60 \%$ of global road traffic deaths. ${ }^{[1]}$ Since developing countries contribute a major share of the global burden of road traffic accidents (RTAs),

\begin{tabular}{|l|l|}
\hline \multicolumn{2}{|c|}{ Access this article online } \\
\hline Quick Response Code: & Website: \\
\hline & www.ruralneuropractice.com \\
\cline { 2 - 2 } & \\
\hline & DOI: \\
\hline
\end{tabular}

cost of dealing with the aftermaths of RTAs (namely management of immediate complications; disability prevention; and long-term rehabilitation services) adds enormously to the already overburdened health care delivery system. $\cdot^{[1,2]}$

Realizing the global public health concern, United Nation has declared the current decade 2011-2020 as the Decade of action for road safety, with a goal of first balancing and then minimizing the anticipated magnitude of RTA-associated mortality. ${ }^{[2]}$ A wide range of socio-demographic parameters such as male gender; ${ }^{[3]}$ young age ${ }^{[3]}$ risk taking behavior; ${ }^{[4]}$ alcohol/psychoactive substances intake; ${ }^{[1,5]}$ non-use of personal protective equipments; ${ }^{[1,4]}$ non-compliance with the traffic rules; $;^{[1,4]}$ and delay in provision of prompt medical care to the victims of RTAs, ${ }^{[1,6]}$ have been identified as potential

\section{Address for correspondence:}

Dr. Saurabh R. Shrivastava, Department of Community Medicine, $3^{\text {rd }}$ Floor, Shri Sathya Sai Medical College and

Research Institute, Ammapettai Village, Thiruporur-Guduvancherry Main Road, Sembakkam, Kancheepuram - 603 108, Tamil Nadu, India.

E-mail: drshrishri2008@gmail.com 
risk factors in the causation or amplification of the consequences of accidents.

Further, in low-resource communities and remote areas (rural/tribal) with long pre-hospital transport times, most trauma deaths have been reported even before the victims reach the hospital. ${ }^{[7-9]}$ In-fact, efficient post-crash response has been acknowledged as one of the five pillars (others being: Road safety management; safer roads and mobility; safer vehicles; safer road users) by the United Nation to bring about a significant reduction in the incidence of RTAs. ${ }^{[2,4]}$ Also, in a non-randomized cohort study done in Iraq, it was observed that efficient pre-hospital trauma system played a critical role in reducing RTA-associated deaths. ${ }^{[10]}$ These facts have seriously necessitated the need for availability and accessibility of good quality pre-hospital care in all areas of the country to minimize the RTA-related morbidity, mortality and disability. ${ }^{[11]}$

Although over the years trauma institutes and emergency ambulance services have been established in the country, but most of them again remain confined to the urban pockets with minimal efforts from the policy makers pertaining to both strengthening of the emergency response system and creating awareness among the people living in rural areas. ${ }^{[12,13]}$ Even findings of studies have shown that factors pertaining to administration and organization, staff qualifications and competencies, availability and distribution of resources, communication and transportation, poor cooperation and coordination, awareness among people, and infrastructure support, either hinder or facilitate an effective pre-hospital trauma care process. ${ }^{[14-16]}$ In addition, there is a dearth of studies done with an aim to assess the effectiveness of pre-hospital care in rural area, South India. Thus, the current study has been planned to assess the attributes of pre-hospital care in RTAs victim brought to the medical college and to evaluate pre-hospital trauma care provided in the rural areas of Kancheepuram district of Tamil Nadu.

\section{Materials and Methods}

A cross-sectional descriptive study of 3 months duration (June 2014 to August 2014) was conducted in the Shri Sathya Sai Medical College and Research Institute, Kancheepuram district, Tamil Nadu - the hospital, Urban Health Training Centre (UHTC) and Rural Health Training Centre (RHTC). Tamil Nadu state lies in the southernmost part of the India and is surrounded by the union territory of Puducherry, Bay of Bengal, and the states of Kerala, Karnataka, and Andhra Pradesh. In India, Tamil Nadu is the $11^{\text {th }}$ largest state by area, $6^{\text {th }}$ most populous state, $3^{\text {rd }}$ most developed state, and ranks second as far as employment percentage is concerned. ${ }^{[17,18]}$ In Tamil Nadu alone in the last 10 years (2005-June 2014), almost 11.9 million new vehicles (transport and non-transport) have been registered, of which ambulances (4489/11934025) constitutes only $0.03 \% \cdot{ }^{[19]}$

The method of sampling was universal sampling and all RTA victims were included in the study. During the entire study duration, total 200 RTA victims were included in the study.

\section{Inclusion criteria}

All victims of RTAs during the study period were included in the study after obtaining their informed consent (for children, informed consent from the guardian/parents will be obtained).

\section{Exclusion criteria}

Those patients who refused to give their informed consent (one subject) or died (three subjects) before the interview were excluded from the study. In addition, unconscious patients and patients who were hemodynamically unstable were also excluded.

\section{Data collection instrument}

A semi-structured questionnaire was used to elicit the desired information. The questionnaire was pre-tested on 10 individuals and based on the obtained responses, the questionnaire was modified. These five subjects were not part of the final study analysis and the modified questionnaire was employed to collect the desired data.

\section{Study variables}

The patients' socio-demographic parameters, place of the accident, the time of accident (day/night), damaged organs, the type of vehicle involved in an accident, pre-hospital care status, pre-hospital time (response time and transport time), and outcome of RTAs.

\section{Methodology}

Once the victims of RTAs are stabilized, all the study participants/guardians (in case of children) were interviewed face to face with the help of the pre-tested semi-structured questionnaire after obtaining their written informed consent. Medical officers of the RHTC and UHTC were explained about the purpose of the study and oriented regarding the different aspects of the questionnaire to enable them to collect the data from their respective centers.

\section{Operational definitions}

Pre-hospital time interval is the sum of response time (time interval between the occurrences of the RTAs 
to arrival of the first responding vehicle on the scene) and transport time (time required for reaching the hospital from the site of the accident). B G Prasad's socio-economic status classification was used to categorize the study participants in different socio-economic class. ${ }^{[20]}$ National classification of occupation was used to categorize the workers into skilled, semi-skilled and unskilled type of occupation. ${ }^{[21]}$

\section{Ethical considerations}

Ethical clearance was obtained from the Institutional Ethics Committee prior to the start of the study. Written informed consent was obtained from the study participants (patient/guardian of children) before obtaining any information from them. Utmost care was taken to maintain privacy and confidentiality. The victims were ensured that findings of the study will not have any implications on their career.

\section{Statistical analysis}

Data entry and statistical analysis were done using SPSS version 18. Frequency distributions and percentages were computed for all the variables.

\section{Results}

Table 1 reflects the distribution of study participants according to their socio-demographic parameters. Majority of the subjects 158 (79\%) were from the age-group of $15-45$ years. Most of the victims were the driver/pillion rider (177/200), while the rest of them were passengers in the four-wheeler/pedestrians (23/200). Out of the 12 subjects who were below 15 years, 10 were travelling in either four-wheeler or motorcycle, while the remaining two got injured while crossing the road. Most of the study participants were males (145/200), educated (181/200), and employed in semi-skilled (127/200) type (namely agriculture, shop, clerk, etc.) of work.

Table 2 demonstrates the multiple attributes of the reported RTAs. Most of the RTAs were reported on Saturday and Sunday (113/200), especially in rural areas (184/200), with most of them being reported in night time as compared to rest of the day. In addition, most of the victims (driver/pillion rider) injured in accidents were travelling on two-wheelers (namely motorcycle, scooter, etc.) than those on four-wheelers. In most of the RTAs, injuries were not restricted to a single body part, with maximum injuries being in upper and lower extremities. However, only 7 (20.6\%) and $33(21.6 \%)$ of the victims were using personal protective measures in four-wheelers and two-wheelers at the time of their accident, respectively. Another 70 (37.4\%) injured victims were either using mobile phones or had consumed alcohol at the time of their accident. Also, only $124(66.3 \%)$ victims had a valid license while remaining $33.7 \%$ were either not having license at all or the license had expired.

Table 3 demonstrates some of the parameters of pre-hospital care. Only 134 (67\%) of the victims were aware of the existence of emergency ambulance services while the rest of them have never heard of the same. Awareness about emergency services in the present study meant that one phone number is available which can be contacted for emergency medical attention at the time of RTAs. Although no precise information was available regarding who called for the ambulance, but most of them was initiated by bystanders or by the victims themselves. Only $15(7.5 \%)$ of the victims were brought to the hospital in the emergency ambulance, while for remaining 185 (92.5\%) cases the ambulance either did not reach or was not called for due to the poor awareness among victims/bystanders, or brought to the hospital by other modes of transport. The ambulance took almost $35 \pm 15$ minutes to reach the site of accident and another $20 \pm 10$ minutes to reach the hospital from the site of accident. Furthermore, in almost $12(80 \%)$ of the ambulances, no attending doctor was present. No data was available about the functional status of

\begin{tabular}{lc} 
Table 1: Socio-demographic parameters of the victims \\
of road traffic accidents \\
\hline Socio-demographic parameters & Number (\%) \\
\hline Age (in years) & \\
$<15$ & $12(6)$ \\
$15-30$ & $107(53.5)$ \\
$30-45$ & $51(25.5)$ \\
$45-60$ & $21(10.5)$ \\
$>60$ & $9(4.5)$ \\
Sex & \\
Male & $145(72.5)$ \\
Female & $55(27.5)$ \\
Religion & \\
Hindu & $178(89)$ \\
Muslim/christian/others & $22(11)$ \\
Education & \\
Illiterate & $19(9.5)$ \\
Primary/middle/high school & $135(67.5)$ \\
Post-high school/graduate and above & $46(23)$ \\
Occupation & \\
Unskilled & $31(15.5)$ \\
Semi-skilled & $127(63.5)$ \\
Skilled & $42(21)$ \\
Socio-economic class & \\
Lower & $16(8)$ \\
Middle & $153(76.5)$ \\
Upper & $31(15.5)$ \\
\hline
\end{tabular}


Table 2: Attributes of road traffic accidents

\begin{tabular}{lc}
\hline Attributes of Accident & Number (\%) \\
\hline Time of accident & $59(29.5)$ \\
Early morning (4 am-8 am) & $23(11.5)$ \\
Day (8 am-4 pm) & $41(20.5)$ \\
Evening (4 pm-8 pm) & $77(38.5)$ \\
Night (8 pm-4 am) & \\
Mechanism of injury & $153(76.5)$ \\
Motorcycle/two-wheeler & $34(17)$ \\
Car/four wheeler & $13(6.5)$ \\
Pedestrian/bicycle/others & \\
Involvement of body parts ${ }^{\star}$ & $133(66.5)$ \\
Upper extremities & $104(52)$ \\
Lower extremities & $24(12)$ \\
Head and neck & $21(10.5)$ \\
Abdomen & $15(7.5)$ \\
Others (back, pelvic region, etc.) & \\
Compliance with safety measures & \\
Car/four-wheeler ( $n=34)^{\star}$ & $7(20.6)$ \\
Use of seat belt & $19(55.9)$ \\
$\quad$ Mobile phone use/alcohol consumption & $26(76.5)$ \\
Valid license & \\
Motorcycle and other two-wheelers ( $n=153)^{\star}$ & $33(21.6)$ \\
Use of helmet & $51(33.3)$ \\
Mobile phone use/alcohol consumption & $98(64.1)$ \\
\hline Valid license &
\end{tabular}

Table 3: Pre-hospital care among victims of RTA

\begin{tabular}{lc}
\hline Pre-hospital care & Number (\%) \\
\hline $\begin{array}{l}\text { Type of interventions done before bringing patient } \\
\text { to the hospital }{ }^{*}(n=200)\end{array}$ & $37(18.5)$ \\
Washing of wound/first-aid & $6(3)$ \\
Splint & $0(0)$ \\
$\quad$ Resuscitation & \\
Arrival of ambulance at the site of accident $(n=200)$ & $15(7.5)$ \\
Yes & $185(92.5)$ \\
No\# & \\
Presence of doctor in ambulance $(n=15)$ & $3(20)$ \\
Yes & $12(80)$ \\
No & \\
Cardio-pulmonary resuscitation services in & \\
ambulance ( $n=15)$ & $2(13.3)$ \\
Yes & $1(6.7)$ \\
No & $12(80)$ \\
Don't know & \\
\#No precise information was available regarding ambulance was called and \\
still it did not reach the site of accident. RTA: Road traffic accidents. ${ }^{*}$ RTA \\
victims had multiple injuries, but no significant first-aid treatment was offered
\end{tabular}

the cardio-pulmonary resuscitation equipment or the competence of the doctor present in the ambulance in carrying out resuscitation activities. Out of the 200 victims of RTA who reached the health care setting, 138 (69\%) were managed on an out-patient basis while remaining $62(31 \%)$ were appropriately managed based on their injuries or clinical condition/referred to higher centers for radiological investigations and further management.

\section{Discussion}

The current descriptive study has been undertaken to assess the status of the emergency trauma system in a rural area. It is one of the very few studies conducted in the rural pockets of South India and thus findings of the study can be an eye-opener for the program managers.

The present study showed that almost 158 (79\%) of the study participants were from the age-group of 15-45 years. Similar sorts of age-group preponderance have been obtained in multiple other cross-sectional studies across diverse settings. ${ }^{[2,23]}$ The people from young age-group were involved in most of the settings as they generally have a risk taking behavior and does not abide with traffic regulations in a consistent manner. However, in contrast to most of the other studies, the study revealed that elderly people were the victims of RTAs. ${ }^{[24]}$ This could be because of the rash driving by the vehicle users or because of the delayed reflexes in the old-age or absence of a companion to guide them while they were using the roads. In-fact, both of these extreme age limits indirectly indicate that not only our society but even the public health professionals is lacking in their efforts to protect and nurture them efficiently.

Also, our study revealed that the male: female ratio among the RTA victims was 2.6:1. In-fact, virtually all the epidemiological studies which have been conducted with an objective to assess the determinants of RTAs have shown that males are more commonly involved in RTAs than the females. ${ }^{[22,24,25]}$ This is primarily because of their risk-taking and fearless nature, peer pressure to drive their vehicles beyond the recommended speed limits as compared to the females who usually abide with traffic regulations. This is not a very new finding, but observing the same trend across different settings is of major concern and reflects the minimum reach of both teachers and the concerned health ministry to reach the most vulnerable section of the society.

The present study depicted that a major proportion (56.5\%) of RTAs were reported on weekends. Some of the other studies also concluded that RTAs were more common during weekends. ${ }^{[26,27]}$ However, in another study to evaluate the effectiveness for emergency dispatch of ambulances, the RTAs were more common in the weekdays. ${ }^{[28]}$ This has been generally attributed to the kind of lifestyle which people adopt in the modern society, where they usually work for 5-6 days a week and weekend is the time to relieve their job-related stress which they might do by consuming alcohol/rash driving, etc. 
The current study and other epidemiological studies have revealed that a major proportion of RTAs was seen in night time. ${ }^{[22,26]}$ Although different explanations, like absence of traffic police, no traffic signals in night time, less traffic and thus people drive beyond the recommended speed limits, have been cited but other than that complete absence/insufficient lights on the roads, especially in rural areas, as observed in present study is a valid explanation which interferes with the vision and augments the chances of human errors.

It was even observed that two-wheelers (namely motorcycle, scooty, etc.) were more commonly involved in accidents than four-wheelers. Again this finding has been supported by different studies and it essentially indicates the unstable nature of the two-wheelers and reinforces the need that motorcyclist should be over-cautious while driving. ${ }^{[23,24,26,27]}$ As evidenced in different studies, even the current study showed that injuries were involving two or more body parts in most of the victims. . $^{[6,8,24,26]}$

Our study even depicted that only $21.4 \%$ (40/187) of the vehicle users were using either helmet or had fastened their seat-belt at the time of their accident. Another study revealed that only $3.1 \%$ of the motorcyclist were wearing a helmet at the time of accident. ${ }^{[29]}$ This is one of the most shocking findings as most of the people are aware of the consequences of head injury, but still they are not wearing the same. ${ }^{[30]}$ However, these results can be biased as it does not suggest any details about use of safety measures among people who were killed at the time of accident. In other words, it reflects ignorance from the people and failure of the public health system to motivate people to use personal protective equipments. At the same time, it provides an opportunity for health professionals/outreach workers to grab this opportunity and work in a strategic manner to bridge this knowledge-application gap. ${ }^{[29,31]}$ Similar explanation stands true for those commuters who were using either mobile phones or had consumed alcohol while driving their vehicles..$^{[1,5]}$ Both of them generally interfere with the judgment and skills which are the key component while driving a vehicle and thus definitely aggravates the incidence of RTAs. ${ }^{[1,5,26]}$

Another finding which questioned the reach of public health services/message was that almost one-fourth of the victims were not aware of the existence of emergency ambulance services. In another study done in Karnataka, almost $72 \%$ of the study participants were aware regarding the emergency ambulance services. ${ }^{[13]}$ In-fact, only $15(7.5 \%)$ of the victims were brought to the health care settings in the emergency ambulance, while for remaining cases the ambulance either did not reach or was not called for due to poor awareness among victims/bystanders. However, these results do not reveal the exact picture as some of the victims who died at the time of accident have not been brought to the hospital and thus were not part of the study. Findings of studies have revealed that in most of the low and middle income nations, the pre-hospital trauma care does not match the expected standards and thus a very few percentage of victims receive treatment at the crash scene and even fewer receive safe transport to the hospital by an ambulance. ${ }^{[11,32,33]}$ This is a serious concern, especially in rural areas, which generally lack adequate health care establishments and transport services $24 \times 7$. However, it will not be right to make any comment regarding the quality/effectiveness of the emergency ambulance services as no precise information was obtained (namely the call has been made but the ambulance did not reach). Nevertheless, this should not be considered as an excuse for $33 \%$ of the victims who were unaware about the same. This calls for a strong campaign involving all stakeholders and should ensure affective community participation to warrant long lasting results and reduce RTA-associated morbidity/mortality.

Furthermore, only three (20\%) of the ambulances had an attending doctor and it again reflects the shortness of the health care professionals in the health sector. Even other studies have documented that injured people are often accompanied by untrained persons like driver or relatives only. ${ }^{[1,32]} \mathrm{At}$ the site of the accident in the present study, very few patients $40(20 \%)$ were given any kind of first-aid treatment. In contrast, other studies have shown a wide range of interventions that should be done as a part of pre-hospital care to improve the outcomes. ${ }^{[34,35]}$

Finally, in our study the ambulance took almost $35 \pm 15$ minutes to reach the site of accident and another $20 \pm 10$ minutes to reach the hospital from the site of accident. This was almost comparable to other studies which have assessed the pre-hospital time interval in a RTA. ${ }^{[14,15,29]}$

The strength of the study is that it was one of the first studies conducted in a rural area of South India to assess the effectiveness of pre-hospital emergency trauma system. In addition, due attention has been paid to cover all the involved variables. However, the present study had its limitation that it was a single institution-based study and thus findings of the study cannot be generalized to the entire South India. In addition, as the study was conducted only among the survivors, thus precise assessment of all the attributes of RTAs could not be achieved. 


\section{Conclusion}

The cross-sectional descriptive study indicates that a significant proportion of people were unaware about the emergency trauma ambulance services and the existing pre-hospital care services lack in multiple dimensions in a rural area of South India. The findings of the study identify the crucial area that is lagging and provide adequate evidence for the program managers to formulate a comprehensive strategy to bridge the existing gap and thus reduce the morbidity and mortality associated with road traffic accidents.

\section{References}

1. World Health Organization. 10 Facts on Global Road Safety, 2013. Available from: http://www.who.int/features/factfiles/roadsafety/en/ index.html\#. [Last accessed on 2014 Aug 22].

2. World Health Organization. Global Plan for the Decade of Action for Road Safety 2011-2020, 2010. Available from: http://www.who.int/ roadsafety/decade_of_action/plan/en/. [Last accessed on 2014 Aug 22].

3. Kanchan T, Kulkarni V, Bakkannavar SM, Kumar N, Unnikrishnan B. Analysis of fatal road traffic accidents in a coastal township of South India. J Forensic Leg Med 2012;19:448-51.

4. World Health Organization. Global status report on road safety-Supporting a decade of action, 2013. Geneva: WHO Press; 2013. p. 4-10.

5. Bogstrand ST, Gjerde H, Normann PT, Rossow I, Ekeberg $\varnothing$. Alcohol, psychoactive substances and non-fatal road traffic accidents--a case-control study. BMC Public Health 2012;12:734.

6. Sánchez-Mangas R, García-Ferrrer A, de Juan A, Arroyo AM. The probability of death in road traffic accidents. How important is a quick medical response? Accid Anal Prev 2010;42:1048-56.

7. Mock C, Arreola-Risa C, Quansah R. Strengthening care for injured persons in less developed countries: A case study of Ghana and Mexico. Inj Control Saf Promot 2003;10:45-51.

8. Montazeri A. Road-traffic-related mortality in Iran: A descriptive study. Public Health 2004;118:110-3.

9. Akbari ME, Naghavi M, Soori H. Epidemiology of deaths from injuries in the Islamic Republic of Iran. East Mediterr Health J 2006;12:382-90.

10. Murad MK, Issa DB, Mustafa FM, Hassan HO, Husum H. Prehospital trauma system reduces mortality in severe trauma: A controlled study of road traffic casualties in Iraq. Prehosp Disaster Med 2012;27:36-41.

11. Sasser SM, Varghese M, Joshipura M, Kellermann A. Preventing death and disability through the timely provision of prehospital trauma care. Bull World Health Organ 2006;84:507.

12. Chaman P. Impact of emergency medical support services on public health delivery system in Goa. BMC Proceedings 2012;6(Suppl 1):14.

13. Lokesh AJ, Thejeshwari HL, Harshwardhan, Siddharam SM. A study on awareness of 108 ambulance services at district hospital in Hassan, Karnataka, South India: A tertiary care hospital attached to Hassan Institute of Medical Sciences (HIMS). Int J Biol Med Res 2013;4:2864-6.

14. Haghparast-Bidgoli H, Hasselberg M, Khankeh H, Khorasani-Zavareh D, Johansson E. Barriers and facilitators to provide effective pre-hospital trauma care for road traffic injury victims in Iran: A grounded theory approach. BMC Emerg Med 2010;10:20.

15. Roudsari BS, Nathens AB, Arreola-Risa C, Cameron P, Civil I, Grigoriou G, et al. Emergency Medical Service (EMS) systems in developed and developing countries. Injury 2007;38:1001-13.

16. Khorasani-Zavareh D, Khankeh HR, Mohammadi R, Laflamme L, Bikmoradi A, Haglund BJ. Post-crash management of road traffic injury victims in Iran. Stakeholders' views on current barriers and potential facilitators. BMC Emerg Med 2009;9:8.
17. Ministry of Home Affairs, India. Census of India 2011. New Delhi Office of the Registrar General and Census Commissioner; 2011. Available from: http://censusindia.gov.in/2011-prov-results/prov_ results_paper1_india.html [Last accessed on 2014 Oct 21].

18. NDTV. Rajan report: Odisha, Bihar least developed; Goa, Kerala on top; 2013.Availablefrom:http://profit.ndtv.com/news/economy/article-rajan -report-odisha-bihar-least-developed-goa-kerala-on-top-327723. [Last accessed on 2014 Oct 21].

19. State Transport Authority, Government of Tamil Nadu. Newly registered vehicle; 2014. Available from: http://www.tn.gov.in/sta/regtrans. PDF. [Last accessed on 2014 Oct 21].

20. Sharma R. Revision of Prasad's social classification and provision of an online tool for real-time updating. South Asian J Cancer 2013;2:157.

21. National Classification of Occupations, 2004. Available from: http:// www.nsdcindia.org/pdf/nco2004-code-structure.pdf. [Last accessed on 2014 Aug 22].

22. Mahajan N, Bhardwaj A, Gupta A, Raina SK, Gupta BP. An epidemiological study on the road traffic accidents from hills of north India. Burn Trauma 2014;2:71-5.

23. Chalya PL, Mabula JB, Dass RM, Mbelenge N, Ngayomela IH, Chandika $\mathrm{AB}$, et al. Injury characteristics and outcome of road traffic crash victims at bugando medical centre in Northwestern Tanzania. J Trauma Manag Outcomes 2012;6:1.

24. Markogiannakis H, Sanidas E, Messaris E, Koutentakis D, Alpantaki K, Kafetzakis A, et al. Motor vehicle trauma: Analysis of injury profiles by road-user category. Emerg Med J 2006;23:27-31.

25. Bhalla K, Naghavi M, Shahraz S, Bartels D, Murray CJ. Building national estimates of the burden of road traffic injuries in developing countries from all available data sources: Iran. Inj Prev 2009;15:150-6.

26. Mishra B, Sinha Mishra ND, Sukhla S, Sinha A. Epidemiological study of road traffic accident cases from Western Nepal. Indian J Community Med 2010;35:115-21

27. Durak D, Fedakar R, Türkmen N, Akgöz S, Baduroğlu E. Road traffic collisions in Bursa, Turkey, during 2003, 2004 and 2005. Injury 2008;39:547-53.

28. Pandey A, Khandekar R. Evaluating the effectiveness of telephone triage for priority emergency ambulance dispatch. J Clin Diagn Res 2009;3:1726-30.

29. Paravar M, Hosseinpour M, Salehi S, Mohammadzadeh M, Shojaee A, Akbari $\mathrm{H}$, et al. Pre-hospital trauma care in road traffic accidents in Kashan, Iran. Arch Trauma Res 2013;1:166-71.

30. Usha M, Ravindran V, Soumithran CS, Ravindran Nair KS. The impact of mandatory helmet law on the outcome of maxilla-facial trauma: A comparative study in Kerala. J Maxillofac Oral Surg 2014;13:176-83.

31. Swaroop M, Marie Siddiqui S, Sagar S, Crandall ML. The problem of the pillion rider: India's helmet law and New Delhi's exemption. J Surg Res 2014;188:64-8.

32. von Elm E. Prehospital emergency care and the global road safety crisis. JAMA 2004;292:923.

33. Kobusingye OC, Hyder AA, Bishai D, Hicks ER, Mock C, Joshipura M. Emergency medical systems in low- and middle-income countries: Recommendations for action. Bull World Health Organ 2005;83:626-31.

34. Gonsaga RA, Valiatti JL, Brugugnolli ID, Gilioli JP, Valiatti MF, Neves N, et al. Evaluation of gasometric parameters in trauma patients during mobile prehospital care. Rev Col Bras Cir 2013;40:293-9.

35. Nevin DG, Green SJ, Weaver AE, Lockey DJ. An observational study of paediatric pre-hospital intubation and anaesthesia in 1933 children attended by a physician-led, pre-hospital trauma service. Resuscitation 2014;85:189-95

How to cite this article: Shrivastava SR, Pandian P, Shrivastava PS Pre-hospital care among victims of road traffic accident in a rural area of Tamil Nadu: A cross-sectional descriptive study. J Neurosci Rural Pract 2014;5:33-8.

Source of Support: Nil. Conflict of Interest: None declared. 